Journal of Social Sciences 7 (4): 586-589, 2011

ISSN 1549-3652

(C) 2011 Science Publications

\title{
Instrument of Primary School Teacher Competency
}

\author{
Abdulghani Mutahar Alnoor and Ma Hongyu \\ Department of Psychology Measurement, College of Psychology, \\ Huazhong Normal University, Wuhan, 430079, Hubei, China
}

\begin{abstract}
Problem statement: The study aimed to investigating the Primary School Teacher Competency (PSTC) and design an PSTC instrument to reflect state standard and use this instrument to compare and evaluate primary school teacher competency. Approach: For this reason, the researcher formulated the following question. What are the necessary teaching competencies of Primary School Teachers (PSTC)? To find answer to the above mentioned questions. Results: The study used the descriptive research approach. To determine the PSTC, the data was collected from specialist's Educators, Teacher's Experience and previous studies which related to the study subject. Conclusion: The study created a list of PSTC consisted of four categories which were category of Knowledge competency, Teaching skills competency, Assessment and Evaluation competency and category of Professional value and Behavior competency.
\end{abstract}

Key words: Primary school teacher, competency instrument, teaching skills, evaluation competency, teacher competency, possible alternatives, mathematics education, enhance learning, possible alternatives educational systems

\section{INTRODUCTION}

As technology changes rapidly recently and during the coming years, the need for Educational training in basic skills will increase dramatically because our entire society is more dependent on science and technology than ever before. In order to meet the challenge of providing adequate training to our younger generation and to meet the minimum requirements of basic skills needed to satisfy today's complex society.

Educational change requires the introduction of new ideas, artifacts, procedures or processes. Innovation demands both initiative and originality. Its aim is to develop and promote change aimed at improving curricula, teaching and learning and the institutional framework in which the change occurs (Alnoor and $\mathrm{Yu}, 2008$ ).

Many of the ideas and principles associated with this learning and the teaching which facilitates it, derive from writing during earlier times (Smith, 2003).

Many Educational studies have provided opportunities for researchers, educators and policymakers to examine their own educational systems and to develop the best possible alternatives to curricula and instruction. During the past several decades, there has been considerable attention to cross national comparisons of education. There is a remarkable growth in international dimension in mathematics education (Bishop, 1992). According to Grouws (2006), the reasons for the growth are varied. First, in every country, mathematics is an important part of the curriculum, usually considered the second most important subject after the native language. Second, there are many similarities in the content of mathematics curricula among countries. Third, the language of mathematics is truly universal. Different cultures and societies have different philosophies regarding the teaching and learning of mathematics these variations of beliefs and values concerning mathematics education result in different education system. The differences include the designing of curricula, the use of textbooks and teaching methods. There are also similar issues in education that many countries share. For example, the search for how to develop effective and efficient education is a common goal in countries around the world (Spaulding, 1989). Many comparative studies have provided opportunities for researchers, educators and policymakers to examine their own educational systems and to develop the possible alternatives to curricula and instruction

A common source for identifying competencies and effectiveness teachers is the judgment of experts/professionals/practitioners, identified the characteristics of effective teachers from the judgments of secondary school teachers and principals.

Corresponding Author: Ma Hongyu, Department of Psychology Measurement, College of Psychology, Huazhong Normal University, Wuhan, 430079, Hubei, China 


\section{J. Social Sci., 7 (4): 586-589, 2011}

In one of the earliest attempts on determining the essential competencies of a teacher (Starr, 1974) the perception of a group of experts consisting of university professors, public school teachers and public school principals were taken as the basis. Mishra (1992) and AlSharif (2010) had used the judgment of teacher Educators and teachers apart from literature analysis for identifying expected performance from science teachers (Bath, 2001) identified

The competencies expected among primary school teachers through:

- Literature and document analysis

- Curriculum analysis and

- Teacher educators' preceptor

Study instrument: To achieve the aim of the study, the researchers developed an instruments questionnaire. The questionnaire is a tool that is consisted of a group of questions or sentences that are required to be answered in a way that is defined by the researcher according to the research purposes.

Questionnaires are the most frequently used data collection method in educational and evaluation research. Questionnaires help gather information on knowledge, attitudes, opinions, behaviors, facts and other information (Radhakrishna, 2008).

The questionnaire used in this study was developed by the researcher, to identify the Primary School Teacher Competencies (PTC), which must primary teacher be available. The researcher according to the research purposes takes the following steps to design the questionnaire.

Offer an opened questionnaire to the experiences teachers and educational specialists contained the following questions:

- How do you usually prepare your lesson before the beginning of the class

- At what level do you think that, the students are in need to study mathematics

- The teaching goals can be divided into many kinds; according to your own point of view, what are these kinds

- How do you deal with the relationship between teaching and life experience of students

- How do you plan to form the "thought pattern learning" of the students

- What functions does the interaction between teachers and students play in the classroom

- How do you lead the students to learn actively

- what are the basic skills do you think that a competent primary school teacher should have
- What should you do to help weak student to learn activity

- What are some ways would you try to motivate students to learn activity

- Analysis of the questionnaire responses

- Informing the earlier researches and studies results in that field

Then the researcher carried out converting each competency to behavioral action. Carried out by the teacher and accordingly, the researcher has designed the PSTCS (Primary School Teaching Competencies scale), contain 67 items altogether. Each items is responded to on a five-point scale with alternatives of Essential, Very important, Important, Unimportant, Not applicable, in its initial shape.

Apparent truthfulness by submitting such questionnaire to a group consist of 20 experts in addition to those who study in the Education Sector, to gather their opinion regarding the extent of the suitability of each competency for the research topic and to classify each competency in the major field that is belong to. The assessors expressed in general the questionnaire validity and they considered it trustworthy, therefore they maintained the majority of the competency items where all the assessors unanimously agreed on its soundness. Then some items were amended and others were deleted according to their point of view. The questionnaire in final shape

Knowledge: Knowledge refers to the content knowledge, professional knowledge, emerging and contemporary knowledge and the practical understanding that a teacher needs in order to perform his or her duties:

- Has a thorough knowledge and understanding of the curriculum and applies this effectively in teaching, making connections across subject matters where applicable

- Believe that all their students have the capacity to learn and should be treated justly and equitably

- Understand the responsibilities and obligations of belonging to the profession of teaching

- Have an understanding of how students develop and how they learn

- Has a sound command of the subject content taught

- Has knowledge of the sociology, philosophy and management of education

- Has basic knowledge of child development/psychology including psychosocial issues and applies these in teaching 
- Knows and applies the rules and policies of the Ministry of Education

- Has knowledge and appreciation of approaches to teaching and learning and related methodologies and applies these in the classroom appropriately

- Has a sound knowledge of the instructional language in spoken and written forms and is able to transfer that knowledge to learners

- Has knowledge of the heritage, values, customs and traditions of society and how these affect individual learners

- Is aware of the legal requirements (statutory framework) relating to teachers' responsibilities and children's rights and works within them

- Has knowledge of a wide range of strategies to enhance access and retention of learners in school, particularly vulnerable children and girls

- Understands the importance of inclusive education and is able to assist learners with special needs

Teaching skills: Teaching Skills refers to the instructional processes, strategies and classroom management techniques that a teacher uses to enhance learning:

- Interprets syllabus content and prepares both schemes of work and daily lesson plans with clear achievable objectives

- Matches content, teaching approaches and student development and learning in planning

- Demonstrated high quality classroom teaching skills which enable all students to achieve their full potential.

- Using gesture and body movement effectively

- Uses information technology to enhance children's learning

- Selects from a variety of teaching methods according to the purpose making maximum use of a variety of learner-centered methodologies appropriate to the age and developmental level of the child

- Listen carefully to children's answers

- Give everyone a chance to answer at some times

- Giving alternative explanations/descriptions of difficulty concepts/ideas/issues

- Using voice effectively through speaking to (not at) the student

- $\quad$ repares appropriate learning materials for pupils

- Develops relevant and appropriate teaching/learning materials using locally available materials as applicable
- Is able to adapt the curriculum and make learning relevant to all learners including those who are special or disadvantaged

- Uses available modern technology to enhance learning

- Takes account of pupils diversity of talents

- Is conscious of the differences in learners and teaches each individual learner in the class, taking into account differences in learning styles, abilities, gender, ages, needs, skills, activities, prior knowledge, psychosocial needs and behavior

- Is able to make a smooth transition between learning activities or lessons

- Possesses good communication skills, both verbal and non-verbal and presents new material clearly, gives clear instructions and checks for understanding and output

- Creates a positive atmosphere in the classroom conducive to learning and motivates learners through appropriate supportive actions

- Modifies his or her language according to the level of the learners taking into consideration their stage of development and mental age and uses both verbal and non-verbal means to aid understanding and enhance learning

- Is able to manage large, mixed ability and multilevel classes effectively

- Monitors student progress and provides feedback on progress

- Makes sure that maximum time is spent on learning by getting and keeping learners' attention and by establishing routines to manage activities

- Promotes accelerated learning through group work and team teaching

- Is able to use a range of behavior management strategies to minimize disruptions and enhance learning

Assessment and evaluation: Assessment and Evaluation refers to the process of collecting, analyzing, interpreting and communicating information about learners' performance using a range of tools to indicate levels of achievement and give feedback of effectiveness of instruction.

The teacher:

- Designs appropriate, valid and reliable assessment tools

- Monitoring and assessing student progress and learning outcomes

- Evaluates teaching and learning programs

- Uses feedback from assessment tools to plan and organize for remedial work

- Provides learners with informative feedback so that they are clear on what has been achieved and what they can do to improve or develop 


\section{J. Social Sci., 7 (4): 586-589, 2011}

- Keeps accurate progress records that help in guidance and counseling and decision-making in terms of planning, promotion

- Maintains records of student progress

- Keeps accurate records on learners' health

- Uses appropriate assessment criteria to make formative and summative judgments about attainment

- Reflects on his/her own teaching in order to continue improving the quality of the learning experience of students

- Monitors learners' progress during and after the lesson through quizzes, assignments, class participation and tests (written or oral)

- Uses assessment tools to identify learners' challenges, potentials or talents

- Ability to assess and monitor student achievement and to provide reports to parents which keep

- them regularly and fully informed of their children's progress

- Applies ethical assessment practices and ensures confidentiality of information

Professional value and behavior: Professional Values refers to the teachers' mode of conduct, ethics, high standards of commitment towards their professional role and promotion of good citizenship.

The teacher:

- Is a role model within the school and in society, both through behavior and appearance

- Develops positive relationships with students

- Is a good citizen and develops a positive attitude of citizenship, patriotism, nationalism and international awareness in the learner and self

- Is a good citizen and develops a positive attitude of citizenship, patriotism, nationalism and international awareness in the learner and self

- Establishes and maintains effective collaboration between and among fellow teachers, learners, parents and all other stakeholders in education

- Provides helpful reports to parents on their children's progress

- Articulates and generates enthusiasm for learning, modeling the skills of a life-long learner and works towards personal educational development

- Works in partnership with stakeholders showing awareness of their rights and interests

- Values respect, discipline and esteem for self, learners and others and values and responds positively to diversity and promotes equity

- Values time management in terms of punctuality, instruction and attendance to duty

- Creates a safe, healthy, supportive and stimulating learning environment

- Uses the outcomes of assessment, as appropriate, in order to evaluate teaching and plan for the future
- Communicates effectively, where appropriate, with representatives of the community of which the school is part

- $\quad$ Relates effectively with parents

\section{CONCLUION}

The study created a list of PSTC for primary School teacher, the list consisted from four categories according to their functions, which was; category of Knowledge, teaching skills category, assessment and evaluation and professional value and behavior category.

\section{ACKNOWLEDGEMENT}

This study is funded by National Education Sciences planning project (BBA090066) and CCNU project of Innovation for National Teacher Education (985zb0303).

\section{REFERENCES}

Alnoor, A. and M.H. Yu, 2010. Yemenis Primary school teacher competency. J. Soc. Sci., 5: 414-420. DOI: 10.3923/sscience.2010.414.420

Al-Sharif, E.M., 2010. Evaluation of Student / Teacher Teaching Competencies in the Curricula and Teaching Methods of Motor Expression in the Light of Quality Academic Standards. World J. Sport Sci., 3: 331-358.

Bath, V.D., 2001. Development of a replicable training strategy for development of essential competencies among primary teachers. A DPEP Project Report.

Grouws, D.A., 2006. Handbook of Research on Mathematics Teaching and Learning. 1st Edn., Information Age Publishing, ISBN: 10: 1593115989, pp: 784.

Mishra, A., 1992. Performance Discrepancy of Science Teachers. 1st Edn., Kanishka Publishing House, New Delhi, ISBN: 10: 8185475105.

Radhakrishna, R.B., 2008. Tips for Developing and Testing Questionnaires/Instruments. University Park, Pennsylvania.

Smith, D., 2003. Learning, Teaching and Innovation A Review of Literature on Facilitating Innovation in Students, Schools and Teacher Education with particular emphasis on Mathematics, Science and Technology. The University of Sydney, Sydney, pp: 1-36.

Starr, W.W., 1974. A Study to Determine the Profile of Essential Teaching Competencies of a Coping First-Year Teacher. 1st Edn., Michigan State University, pp: 344. 